\title{
Beating heart revascularization with or without cardiopulmonary bypass: Evaluation of inflammatory response in a prospective randomized study
}

\author{
Innes Y. P. Wan, FRCSEd ${ }^{\mathrm{a}}$ \\ Ahmed A. Arifi, MD, FRCS \\ Song Wan, MD, FRCS ${ }^{a}$ \\ Johnson H. Y. Yip, MPhil \\ Alan D. L. Sihoe, MRCSEd ${ }^{a}$ \\ K. H. Thung, FRCSEd ${ }^{\mathrm{a}}$ \\ Eric M. C. Wong, $\mathrm{MSc}^{\mathrm{b}}$ \\ Anthony P. C. Yim, MD, FRCS ${ }^{a}$
}

From the Division of Cardiothoracic Surgery, ${ }^{a}$ Department of Surgery, and Centre of Epidemiology and Biostatistics, ${ }^{\mathrm{b}}$ The Chinese University of Hong Kong, Prince of Wales Hospital, Hong Kong SAR, China.

Received for publication Aug 14, 2003; revisions requested Sept 17, 2003; accepted for publication Oct 20, 2003.

Address for reprints: Ahmed A Arifi, Professor, Chief of Cardiac Surgery, Division of Cardiothoracic Surgery, Department of Surgery, The Chinese University of Hong Kong, Prince of Wales Hospital, Shatin, New Territories, Hong Kong SAR, China (E-mail: arifi64@ surgery.cuhk.edu.hk).

J Thorac Cardiovasc Surg 2004;127: 1624-31

$0022-5223 / \$ 30.00$

Copyright () 2004 by The American Association for Thoracic Surgery

doi:10.1016/j.jtcvs.2003.10.043
Objective: On-pump beating heart coronary artery surgery provides the opportunity to examine the isolated effect of cardiopulmonary bypass. This prospective randomized study compares the early clinical outcomes and inflammatory response of patients undergoing elective on-pump and off-pump beating heart coronary artery bypass grafting.

Method and Patients: Thirty-seven consecutive patients undergoing elective coronary artery bypass grafting were recruited from a pool of 73 patients, with 19 patients randomized to on-pump beating heart surgery and 18 patients to off-pump coronary bypass surgery. Intraoperative events and postoperative outcomes were recorded. Plasma levels of interleukin-6, interleukin-8, and interleukin-10, tumor necrosis factoralpha, and vascular cell adhesion molecule-1 were measured before the operation, intraoperatively, after the operation, and 4, 24, and 48 hours thereafter.

Results: There was no significant difference in clinical outcomes between the 2 groups. The operating time was longer and consumption of platelets was greater for the on-pump beating heart group. There was no postoperative mortality or major complication in either group. There was significant elevation in the levels of interleukin-6, interleukin-8, and interleukin-10 and tumor necrosis factor-alpha during and immediately after the operations in the on-pump beating heart group when compared with the off-pump group. Levels of interleukin-8 $(P=.01)$ and tumor necrosis factor-alpha $(P=.0004)$ remained significantly elevated 4 hours after the operation in the on-pump beating heart group. The level of vascular adhesion molecule dropped significantly during the operation but was elevated 4 hours $(P=.026)$ after the operation in the on-pump beating heart group.

Conclusion: The use of cardiopulmonary bypass alone without global myocardial ischemia secondary to aortic crossclamping and cardioplegic cardiac arrest can trigger intense inflammatory responses.

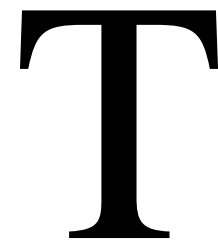

here has been a resurgence of interest in off-pump coronary artery bypass (Off-PCAB) in the last decade, and the advantages associated with the use of this technique have been repeatedly emphasized. Controversies still exist concerning the benefits of Off-PCAB when compared with conventional coronary artery bypass grafting (CABG).$^{1-3}$ The morbidities of conventional CABG include the use of cardiopulmonary bypass (CPB), cardioplegic arrest, and manipulation of aorta 
and median sternotomy as surgical access. Off-PCAB eliminated the use of $\mathrm{CPB}$ and cardioplegic arrest. The use of CPB has been shown to provoke systemic inflammatory response syndrome and is associated with the release of cytokines and activation of complements. ${ }^{4-6}$ Off-PCAB does not mean elimination of the heart-lung machine alone. This technique also eliminates global myocardial ischemia during aortic crossclamping and reperfusion after cardioplegic arrest. ${ }^{7}$ Another important difference in off-pump surgery is the continuous ventilation of the lungs during the operation. The ventilation is usually stopped during conventional CABG performed with CPB. We have studied the cytokine responses using different methods of myocardial protection and even with intermittent aortic crossclamping with fibrillation ${ }^{8}$ but the isolated effect of the heart-lung machine on the body has never been elucidated. The technique of on-pump beating heart coronary artery bypass (On-PCAB) has been reported as an acceptable trade-off between conventional $\mathrm{CABG}$ with cardioplegic arrest and Off-PCAB in selected high-risk patient. ${ }^{9}$ With on-pump beating heart technique and continuous ventilation we could investigate the isolated effect of the CPB machine on the body's inflammatory response without the influence of ischemic reperfusion secondary to cardioplegic arrest. A prospective randomized study was conducted to compare the clinical outcomes and inflammatory response of patients undergoing elective Off-PCAB and On-PCAB.

\section{Patients and Methods}

Thirty-seven consecutive patients undergoing elective CABG were recruited from a pool of 73 patients. Patients with recent myocardial infarction, unstable angina, on steroid treatment, age $>75$, serum creatinine $>200 \mu \mathrm{mol} / \mathrm{L}$, single-vessel disease, previous open cardiac procedures, and poor left ventricular function (ejection fraction $<30 \%$ ) were excluded. With ethical committee approval, written informed consent was obtained from all patients. A randomization table was generated with a computer, and the results were concealed in sealed opaque envelopes. Both the patients and the surgeons were unaware of the result of randomization until the patient was put under general anesthesia and the sealed envelope was opened. One surgeon performed all the operations.

\section{Anesthetic Technique}

Standard anesthetic techniques were employed in all cases with intravenous propofol combined with sufentanil and midazolam. Muscle relaxation was achieved with pancuronium. Prophylatic antibiotic Cefuroxime (GlaxoSmithKline, Hong Kong, China; $1.5 \mathrm{~g}$ ) was given on induction and followed by $750 \mathrm{mg}$ every 8 hours for 24 hours. Ventilation was maintained throughout the operation for both groups of patients. For the On-PCAB group, heparin was given at a dose of $3 \mathrm{mg} / \mathrm{kg}$ with activated clotting time (ACT) greater than 480 seconds while $1.5 \mathrm{mg} / \mathrm{kg}$ of heparin was given for the Off-PCAB group, keeping ACT within the range of 250 to 350 .
Full-dose heparin ( $3 \mathrm{mg} / \mathrm{kg}$ ) was given when ACT was greater than 480 seconds. Mean perfusion pressure was kept at $60 \mathrm{~mm} \mathrm{Hg}$ and patient was kept warm throughout the procedure. On completion of CPB, protamine was given to neutralize the heparin.

\section{Surgical Technique}

Median sternotomy was used as the surgical access in all cases. Left internal thoracic arteries were harvested in all cases and radial arteries or saphenous veins were used as other conduits. In both Off-PCAB and On-PCAB groups, cardiac displacement was achieved by using a half-folded swab being snared down to the posterior pericardium between the left inferior pulmonary vein and inferior vena cava. The swab was used to lift the heart out of the pericardial cradle. ${ }^{10}$ The target vessels were exposed and controlled with silastic sling. Stabilization was achieved with the compression type of stabilizer (Guidant, Santa Clara, Calif). The target vessel was then opened and an intracoronary shunt (Flothru Biovascular Inc, St Paul, Minn) was put in to maintain distal perfusion during the performance of anastomosis. Visualization of the operative field was achieved with carbon dioxide surgical blower system. All proximal anastomoses were performed with the use of side-biting aortic clamp. For the On-PCAB group, standard $\mathrm{CPB}$ technique was employed with ascending aortic cannulation and venous drainage via 2 -stage venous cannula within the right atrium. The circuit consisted of a roller pump (Stockert, GmBH, Germany) and a membrane oxygenator (Capriox SX, Terumo, Mich).

\section{Cytokine and Biochemical Measurements}

Blood samples were taken before the procedure, on completion of distal anastomosis for the Off-PCAB group and on completion of $\mathrm{CPB}$ for On-PCAB group, on skin closure, and 4, 12, and 24 hours after the operations. All blood samples were immediately cooled to $4^{\circ} \mathrm{C}$ and centrifuged ( $3000 \mathrm{~g}$ for 10 minutes at $4^{\circ} \mathrm{C}$ ). The plasma was separated and stored at $-70^{\circ} \mathrm{C}$ until assay. Levels of tumor necrosis factor-alpha (TNF- $\alpha$ ), interleukin (IL)-6, IL-8, IL-10, and vascular adhesion molecule-1 (VCAM-1) were determined by means of commercially available enzyme-linked immunosorbent assays (R\&D Systems, Minneapolis, Minn).

\section{Statistical Methods}

All data were stored and analyzed using a standard computer statistical software program (Statistical Package for the Social Sciences 11.0; SPSS Inc, Chicago, Ill) and MIXREG computer software. ${ }^{11}$ Clinical data were shown as mean \pm standard deviation. Unpaired $t$ test and chi-square test were used for comparing clinical variables between the 2 groups. Mixed-effects models (multilevel models) were used for analyzing longitudinal data ${ }^{12}$ by comparing the cytokine and adhesion molecule levels between the 2 groups at each of the 6 time points. The mixed-effects model is considered to be an extension of the ordinary least-squares regression model but also takes into account subject heterogeneity. The statistical analysis was performed on raw data and logarithmically transformed results where appropriate to correct the skewness of the data. Values of those biochemical data are expressed as mean \pm standard error of the mean. 
TABLE 1. Patient characteristics

\begin{tabular}{|c|c|c|c|}
\hline Preoperative variables & Off-PCAB (n = 18) & On-PCAB (n = 19) & $P$ value \\
\hline Male sex & 15 & 11 & .15 \\
\hline $\mathrm{Age}^{*}$ & $63.61 \pm 10.47$ & $65.37 \pm 9.08$ & .59 \\
\hline \multicolumn{4}{|l|}{ Angina class } \\
\hline I & 0 & 0 & \\
\hline II & 7 & 11 & \\
\hline III & 11 & 8 & \\
\hline IV & 0 & 0 & \\
\hline \multicolumn{4}{|l|}{ NYHA class } \\
\hline I & 0 & 0 & \\
\hline II & 10 & 13 & \\
\hline III & 8 & 6 & \\
\hline IV & 0 & 0 & \\
\hline Hypertension & 13 & 15 & .71 \\
\hline Diabetes & 7 & 6 & .73 \\
\hline Hyperlipidemia & 12 & 15 & .48 \\
\hline Smoking & 11 & 6 & .10 \\
\hline Family history of ischemic heart disease & 6 & 3 & .27 \\
\hline History of myocardial infarction & 4 & 3 & .69 \\
\hline Number of disease vessels* & $2.44 \pm 0.51$ & $2.74 \pm 0.45$ & .075 \\
\hline Ejection fraction* & $52.93 \pm 13.58$ & $50.42 \pm 12.04$ & .57 \\
\hline
\end{tabular}

NYHA, New York Heart Association; Off-PCAB, off-pump coronary artery bypass; On-PCAB, on-pump beating heart coronary artery bypass.

*Mean \pm standard deviation.

\section{Results}

\section{Clinical Outcomes}

The Off-PCAB and On-PCAB groups were comparable in terms of age, sex, functional class, and number of disease coronary vessels (Table 1). There was no major complication in either group and no patient required reexploration for bleeding. The mean number of grafts was $2.44 \pm 0.51$ for the Off-PCAB group and $2.79 \pm 0.54$ for On-PCAB group (Table 2). The operating time was significantly longer for the On-PCAB group (mean $=167.10 \pm 36.91$ minutes) when compared with the Off-PCAB group (mean $=143.61$ $\pm 29.2 ; P=.038$. There was no 30-day mortality for either group. None of the patients suffered from postoperative myocardial infarction, cerebrovascular accident, renal failure, or low cardiac syndrome. There was no significant statistical difference in the frequency of atrial fibrillation or flutter between the 2 groups $(P=1.00)$.

\section{Cytokines and Adhesion Molecules}

Levels of IL-6 were raised in both groups during and after the operations. IL-6 levels were significantly higher in the On-PCAB group intraoperatively and immediately after the operation when compared with the Off-PCAB group $(P=$ $.0023, P=.0002$, respectively; Figure 1$)$. IL-8 levels were significantly higher in the On-PCAB group but the difference disappeared 24 hours after the operation $(P<.0001, P$ $<.0001$, and $P=.01$, respectively; Figure 2). IL-10 levels were elevated in both groups but the levels were significantly higher in the On-PCAB group during and immediately after the operation $(P<.0001$ and $P<.0001$, respec- tively; Figure 3). TNF- $\alpha$ levels were significantly elevated in the On-PCAB group during the operation, immediately after, and 4 hours after $(P<.0001, P<.0001$, and $P=$ .0004 , respectively; Figure 4$)$. There was a drop in the VCAM-1 levels during the operation in the On-PCAB group $(P=.0006)$ but significantly higher levels were observed 4 hours after the operation when compared with the Off-PCAB group $(P=.026$; Figure 5).

\section{Discussion}

The morbidities of conventional CABG have been attributed to the use of $\mathrm{CPB}$, cardioplegic arrest, and aortic crossclamping resulting in ischemia and reperfusion. The development of off-pump CABG served to eliminate the harmful effects of the heart-lung machine together with cardioplegia. The clinical and biochemical benefits of offpump surgery have been demonstrated in various clinical trials. ${ }^{3-5}$ On-pump beating heart coronary operations have been described as an acceptable trade-off in high-risk patients as manipulation of the heart during off-pump grafting would lead to significant hemodynamic compromise with decrease in cardiac output and stroke volume. ${ }^{9}$ No randomized prospective study is available in the current literature that investigates the effect of CPB in isolation. This study serves to eliminate the effects of global myocardial ischemic arrest using aortic crossclamping and cardioplegic arrest and allows observation of the clinical and biochemical consequences of on-pump beating heart coronary operations. 


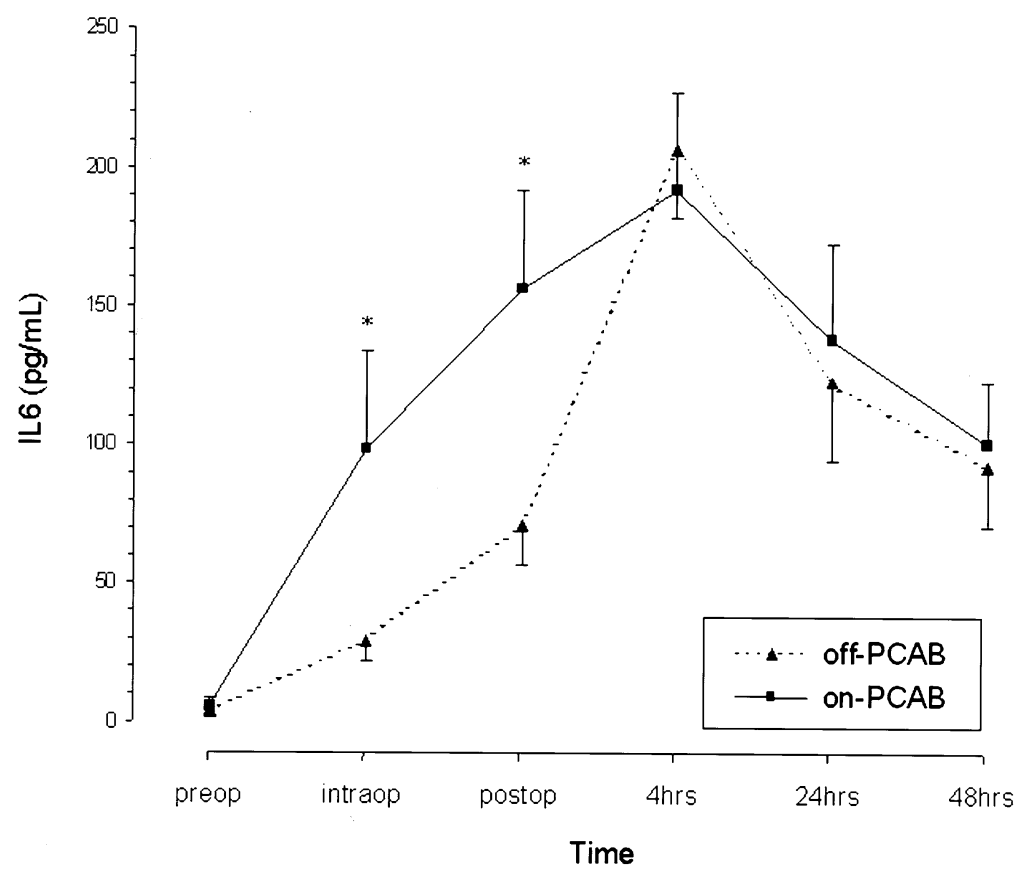

Figure 1. IL-6 $(\mathrm{pg} / \mathrm{mL})$ in patients receiving On-PCAB $(\mathrm{n}=19)$ and Off-PCAB $(\mathrm{n}=18)$ over the study period. The asterisks indicate significant rate of change in IL-6 compared with preoperative concentration between the 2 groups. Preop, Preoperative; Intraop, intraoperative; Postop, immediately postoperative and 4, 24, and 48 hours after the operation. Data are given as means \pm SEM.

TABLE 2. Perioperative variables

\begin{tabular}{|c|c|c|c|}
\hline Perioperative variables & Off-PCAB (n = 18) & On-PCAB (n = 19) & $P$ value \\
\hline Operation time $(\min )^{*}$ & $143.61 \pm 29.20$ & $167.10 \pm 36.91$ & .038 \\
\hline Number of grafts* & $2.44 \pm 0.51$ & $2.79 \pm 0.54$ & .053 \\
\hline Postoperative bleeding & 0 & 0 & \\
\hline Blood loss ( $\mathrm{mL}$ in 24 hours)* & $701.17 \pm 243.71$ & $748.16 \pm 305.94$ & .61 \\
\hline Time to extubation (hours) & $6.08 \pm 2.52$ & $7.32 \pm 2.60$ & .15 \\
\hline Duration of ICU stay (hours) ${ }^{*}$ & $18.94 \pm 4.57$ & $18.74 \pm 2.88$ & .87 \\
\hline Postoperative $\mathrm{MI}$ & 0 & 0 & \\
\hline Atrial fibrillation/flutter & 2 & 3 & .661 \\
\hline Ventricular fibrillation/tachycardia & 0 & 0 & \\
\hline Postoperative stroke & 0 & 0 & \\
\hline Postoperative renal failure & 0 & 0 & \\
\hline Use of intra-aortic balloon pump & 0 & 0 & \\
\hline Low cardiac output syndrome & 0 & 0 & \\
\hline Length of hospital stay (days) ${ }^{*}$ & $6.06 \pm 1.21$ & $6.26 \pm 0.99$ & .57 \\
\hline
\end{tabular}

Off-PCAB, Off-pump coronary artery bypass; On-PCAB, on-pump beating heart coronary artery bypass; ICU, intensive care unit; $M I$, myocardial infarction. ${ }^{*}$ Mean \pm standard deviation.

We and other groups have demonstrated the association of reduced proinflammatory response with the off-pump technique. ${ }^{3-5}$ In this study we showed that the use of CPB in isolation without the effect of global myocardial ischemia was associated with the rise in proinflammatory cytokines and adhesion molecules. CPB is the major factor in triggering the inflammatory response during CABG. However, we could not demonstrate any significant clinical outcomes between the 2 groups of patients except the greater requirement of platelet transfusion for the On-PCAB group (Table $3)$. The operating time was longer for the On-PCAB group as extra time was needed for the setup of CPB and cannulation.

The contact of blood with CPB surface, ischemia and reperfusion, and surgical trauma can trigger the release of inflammatory mediators including complements and cyto- 


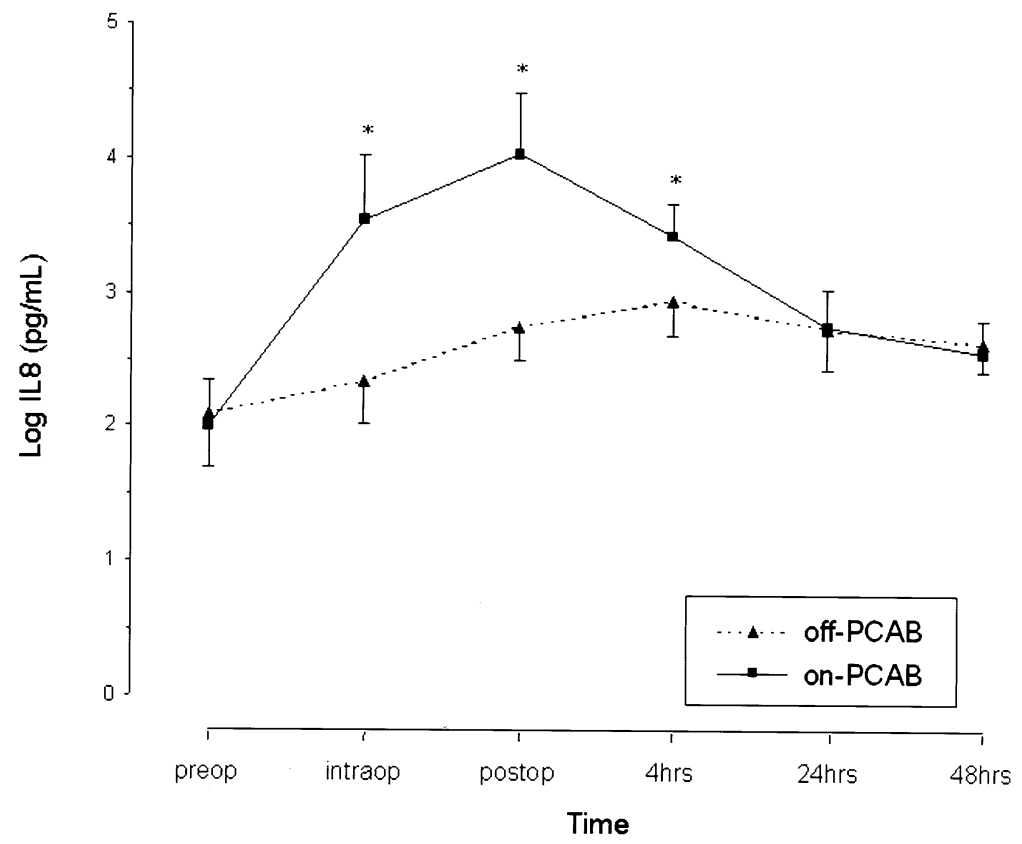

Figure 2. IL-8 $\left(\mathrm{pg} / \mathrm{mL} ; \log _{\mathrm{e}}\right)$ in patients receiving On-PCAB $(\mathrm{n}=19)$ and Off-PCAB $(\mathbf{n}=18)$ over the study period. The asterisks indicate significant rate of change in IL-8 compared with preoperative concentration between the 2 groups. Preop, Preoperative; Intraop, Intraoperative; Postop, immediately postoperative and 4, 24, and 48 hours after the operation. Data are given as means \pm SEM.

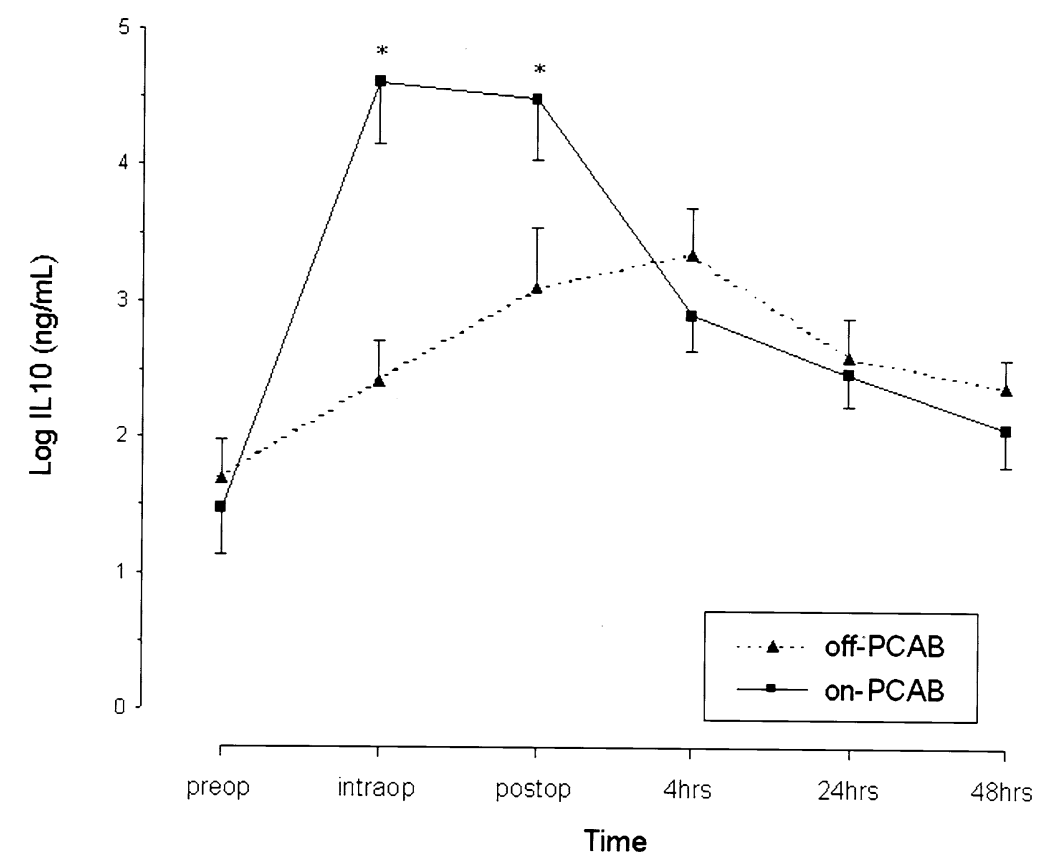

Figure 3. IL-10 $\left(\mathrm{pg} / \mathrm{mL} ; \log _{\mathrm{e}}\right)$ in patients receiving On-PCAB $(\mathrm{n}=19)$ and Off-PCAB $(\mathrm{n}=18)$ over the study period. The asterisks indicate significant rate of change in IL-10 compared with preoperative concentration between the 2 groups. Preop, Preoperative; Intraop, intraoperative; Postop, immediately postoperative and 4, 24, and 48 hours after the operation. Data are given as means \pm SEM. 


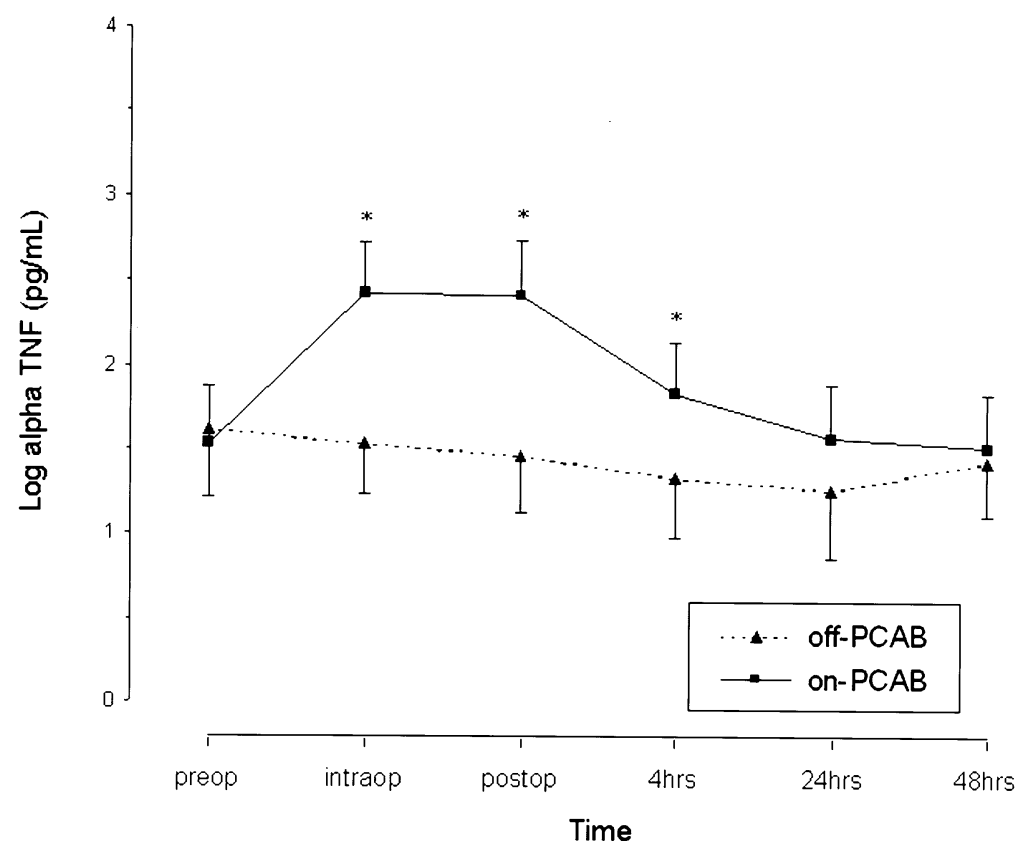

Figure 4. TNF- $\alpha\left(\mathrm{pg} / \mathrm{mL} ; \log _{\mathrm{e}}\right)$ in patients receiving On-PCAB $(\mathrm{n}=19)$ and Off-PCAB $(\mathrm{n}=18)$ over the study period. The asterisks indicate significant rate of change in TNF- $\alpha$ compared with preoperative concentration between the 2 groups. Preop, Preoperative; Intraop, intraoperative; Postop, immediately postoperative and 4, 24, and 48 hours after the operation. Data are given as means \pm SEM.

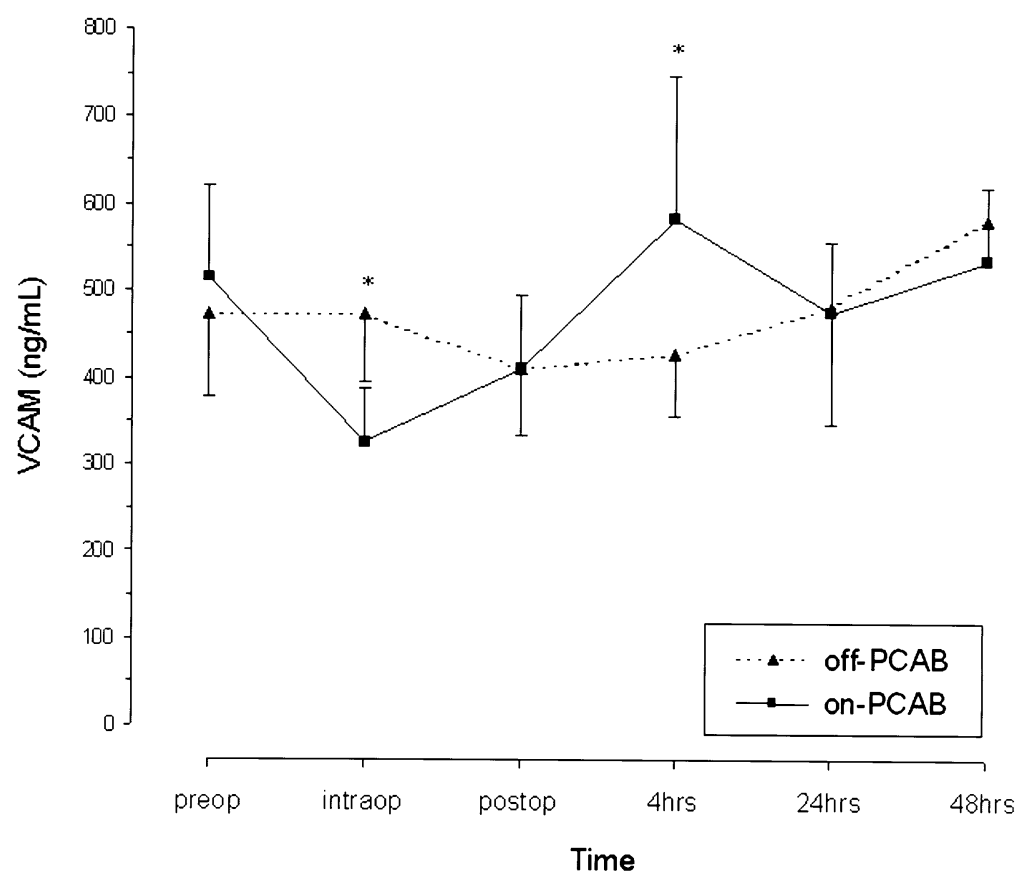

Figure 5. VCAM-1 $(\mathrm{ng} / \mathrm{mL})$ in patients receiving On-PCAB $(\mathrm{n}=19)$ and Off-PCAB $(\mathrm{n}=18)$ over the study period. The asterisks indicate significant rate of change in VCAM-1 compared with preoperative concentration between the 2 groups. Preop, Preoperative; Intraop, intraoperative; Postop, immediately postoperative and 4, 24, and 48 hours after the operation. Data are given as means \pm SEM. 
TABLE 3. Blood products usage

\begin{tabular}{lrrr}
\hline Blood products & $\begin{array}{r}\text { Off-CAB } \\
\text { (n= 18) }\end{array}$ & $\begin{array}{c}\text { On-CAB } \\
(\mathbf{n}=19)\end{array}$ & P value \\
\hline $\begin{array}{l}\text { Blood (units) } \\
\text { Fresh frozen plasma } \\
\quad \text { (units) }\end{array}$ & $0.44 \pm 0.86$ & $1.11 \pm 1.41$ & .093 \\
Platelets (units) & $0.15 \pm 0.49$ & $1.70 \pm 0.73$ & .108 \\
\hline
\end{tabular}

*Mean \pm standard deviation.

kines. ${ }^{13}$. The nuclear factor $\mathrm{kB}$ is activated by the release of cytokines and subsequently translocated to the nucleus, and the expression of several inflammatory mediators is induced. The expression of adhesion molecules including intercellular adhesion molecule and VCAM is upgraded by the release of cytokines. The binding of adhesion molecules with the integrins triggers the firm adhesion of leukocytes on the endothelial cells. The leukocytes can migrate across the endothelial cells into the interstitial space, releasing free oxygen free radicals, arachidonic acid metabolites, and proteases. ${ }^{13}$ All these result in endothelial dysfunction and may be associated with postoperative complications after cardiac surgery. Our study shows that the contact of blood with the CPB surface appears to be the most important factor in the initiation of the systemic inflammatory response with surgical trauma and ischemia and reperfusion playing a less important role.

IL-6, IL-8, and TNF- $\alpha$ are proinflammatory cytokines and their increase was previously shown to be associated with hemodynamic instability and myocardial dysfunction after CPB. ${ }^{14}$ The rise in IL-6 was observed in both groups of patients as the release of IL-6 was associated with surgical trauma. However, there was still significant difference in the rise of IL-6 levels intraoperatively and immediately after the operation. It has been shown that ischemia and reperfusion result in induction of IL- 6 mRNA production by cardiac myocytes. ${ }^{15}$ In situ hybridization studies confirmed that myocardium was a principal source of IL-6 synthesis after cold cardioplegic arrest and $\mathrm{CPB} .{ }^{16}$ Our study shows that with $\mathrm{CPB}$ alone without cardioplegia, significantly higher levels of IL- 6 can be detected during the operation when compared with the off-pump group.

IL-8 was shown to be released from the myocardium during ischemia and reperfusion. ${ }^{17}$ We have previously demonstrated the positive correlation between the cardiac troponin I and elevated IL-8 levels after cardiac surgery. ${ }^{4}$ Our study shows that CPB alone without ischemia and reperfusion can result in a significant rise in IL-8.

TNF- $\alpha$ level rose significantly during and after the CPB operations. This result further supports the fact that the heart-lung machine is the main trigger of proinflammatory cytokines, which we failed to demonstrate in our previous study. ${ }^{4}$ The myocardium has been implied as the source of
TNF- $\alpha$ release after ischemia-reperfusion injury in experimental studies and it was shown to inhibit hamster papillary muscles in a dose-dependent manner. ${ }^{18}$

Induction of IL-10 was demonstrated in reperfused myocardium following ischemia, and it helped to suppress the acute inflammatory response by modulating macrophagecytokine function and promote metabolic steps associated with tissue repair. ${ }^{19}$ The release of IL-10 is lower during off-pump surgery when compared with the on-pump beating heart surgery. The lower release of this anti-inflammatory cytokine for the off-pump group may be related to the less intense proinflammatory response. Accumulating evidence shows that the balance between pro- and anti-inflammatory mediators is crucial in determining the outcome of inflammatory injury. ${ }^{4,20,21}$ As most of these pro- and anti-inflammatory cytokines were produced by the myocardium, cardioplegic arrest and reperfusion could result in direct myocardial injury with induction of all these cytokines. Theoretically, with elimination of the ischemia-reperfusion insult imposed by cardioplegia and aortic crossclamping, all these cytokine responses should be attenuated. However, we show that use of CPB alone with both lungs being ventilated results in a significant rise in all the cytokines, but we cannot prove whether the myocardium is the source, as previous study showed. Further studies including coronary sinus blood sampling of cytokines may help to determine the source of the cytokines, and currently we have no evidence of cytokine release from myocardium under the influence of nonpulsatile flow with the use of CPB alone.

Circulating soluble adhesion molecules from endothelial cells were considered to be the reflection of cellular activation and damage. ${ }^{22}$ VCAM-1 belongs to the group of transmembrane glycoproteins of the immunoglobulin superfamily expressed by the endothelial cells. It serves as a ligand for leukocyte integrins. ${ }^{23}$ Serum VCAM-1 was demonstrated to be a very early marker of endothelial activation and damage caused by CPB. The release of VCAM- 1 has been shown to be related to the use of CPB and also to ischemia and reperfusion after cardioplegic arrest. ${ }^{24} \mathrm{We}$ showed that there was a rise in the level of VCAM-1 4 hours after the operation with CPB alone without the use of cardioplegia in the aortic crossclamping group but we could not explain a why there was a drop in VCAM-1 level intraoperatively for the On-PCAB group. It is unclear whether the rise in the VCAM-1 level is secondary to increased cellular expression or shedding from the cells. Recent study has supported the cleavage of cell-surface adhesion molecule rather than increased endothelial cell synthesis or expression. IL-10 can suppress adhesion molecule expression $^{25}$ and can possibly explain the normalization of VCAM-1 24 hours after the operation. The rise in the VCAM-1 levels appears to be delayed when compared with other inflammatory cytokines. This can be explained by the 
fact that the activation of VCAM- 1 consists of 2 phases involving gene regulation and induction of protein synthesis. $^{26}$

The use of CPB alone has been shown to be associated with a significant rise in the inflammatory response when compared with off-pump coronary artery bypass surgery. It seems that the modification of different cardioplegic techniques without elimination of CPB may not be helpful in abolishing the body's inflammatory response. The increase in systemic inflammatory response results in leukocyte extravasation, tissue damage, myocardial suppression, and ultimately organ failure. Any strategy that reduces systemic inflammatory response can theoretically minimize the morbidities associated with coronary artery surgery.

\section{Conclusion}

The use of CPB alone without global myocardial ischemic arrest secondary to aortic crossclamping and cardioplegia can trigger intense inflammatory responses.

\section{References}

1. Yacoub M. Off-pump coronary bypass surgery: in search of an identity. Circulation. 2001;104:1743-5.

2. Van Dijk D, Nierich AP, Jansen EWL, Nathoe HM, Suyker WJL, Diephuis JC, et al. Early outcome after off-pump versus on-pump coronary bypass surgery. Results from a randomized study. Circulation. 2001;104:1761-6.

3. Ascione R, Caputo M, Angelini GD. Off-pump coronary artery bypass grafting: not a flash in the pan. Ann Thorac Surg. 2003;75:306-13.

4. Wan S, Izzat MB, Lee TW, Wan IYP, Tang N, Yim APC. Avoiding cardiopulmonary bypass in multivessel CABG reduces cytokine response and myocardial injury. Ann Thorac Surg. 1999;68:52-7.

5. Paparella D, Yau TM, Young E. Cardiopulmonary bypass induced inflammation: pathophysiology and treatment. An update. Eur J Cardiothorac Surg. 2002;21:232-44.

6. Ascione R, Lloyd CT, Underwood MJ, Lotto A, Pitsis AA, Angelini GD. Inflammatory response after coronary revascularization with or without cardiopulmonary bypass. Ann Thorac Surg. 2000;69:1198204.

7. Wan S, Yim AP, Ng SH, Arifi AA. Systematic organ protection in coronary artery surgery with or without cardiopulmonary bypass. $J$ Card Surg. 2002;17:529-35.

8. Wan S, Arifi AA, Wan IYP, Ng SH, Lee TW, Yim APC. Cytokine responses to myocardial revascularization on cardiopulmonary bypass: intermittent crossclamping versus blood cardioplegic arrest. Ann Thorac Cardiovasc Surg. 2002;8:12-17.

9. Perrault LP, Menasche P, Peynet J, Faris B, Bel A, De Chaumaray T, et al. On-pump, beating heart coronary artery operations in high risk patients: an acceptable trade-off. Ann Thorac Surg. 1997;64:1368-73.
10. Ricci M, Karamanoukian H, D’Ancona G, Bergsland J, Salerno TA. Exposure and mechanical stabilization in off-pump coronary artery bypass grafting via sternotomy. Ann Thorac Surg. 2000;70:1736-40.

11. Hedeker D, Gibbons RD. MIXREG: a computer program for mixedeffects regression analysis with autocorrelated errors. Comput Meth Prog Biomed. 1996;49:229-52.

12. Goldstein H, editor. Multilevel statistical models. In: Kendall's library of statistics 3. London: Edward Arnold; 1995. p. 87-94.

13. Grunenfelder J, Zund G, Schoeberlein A, Schurr U, Frisullo R, Schmid ER, et al. Expression of adhesion molecules and cytokines after coronary artery bypass grafting during normothermic and hypothermic cardiac arrest. Eur J Cardiothorac Surg. 2000;17:723-8.

14. Wan S, DeSmet JM, Barvais L, Goldstein M, Vicent JL, LeClerc JL. Myocardium is a major source of proinflammatory cytokines in patients undergoing cardiopulmonary bypass. J Thorac Cardiovasc Surg. 1996;112:806-11.

15. Kukielka GL, Smith W, Manning AM, Youker KA, Michael LH, Entman ML. Induction of interleukin-6 synthesis in the myocardium. Circulation. 1995;92:1866-75.

16. Dreyer WJ, Phillips SC, Lindsey ML, Jackson P, Bowles NE, Michael $\mathrm{LH}$, et al. Interleukin-6 induction in the canine myocardium after cardiopulmonary bypass. J Thorac Cardiovasc Surg. 2000;120:25663.

17. Ivey CL, Williams FM, Collins PD, Jose PJ, Williams TJ. Neutrophil chemoattractants generated in two phases during reperfusion of ischemic myocardium in the rabbit: evidence for a role for $\mathrm{C} 5 \mathrm{a}$ and interleukin-8. J Clin Invest. 1995;95:2720-8.

18. Finkel MS, Oddis CV, Jacob TD, Watkins SC, Hattler BG, Simmons RL. Negative inotropic effects of cytokines on the heart mediated by nitric oxide. Science. 1992;257:387-9.

19. Frangogiannis NG, Mendoza LH, Lindsey ML, Ballantyne CM, Michael LH, Smith CW, et al. IL-10 is induced in reperfused myocardium and may modulate the reaction to injury. J Immunol. 2000;165:2798808 .

20. Wan S, LeClerc JL, Vincent JL. Inflammatory response to cardiopulmonary bypass: mechanisms involved and possible therapeutic strategies. Chest. 1997;112:676-92.

21. Wan S, LeClerc JL, Antoine M, DeSmet JM, Yim APC, Vicent JL. Heparin-coated circuits reduce myocardial injury in heart or heart-lung transplantation: a prospective randomized study. Ann Thorac Surg. 1999;68:806-11.

22. Andresen TK, Svennevig JL, Videm V. Soluble VCAM-1 is a very early marker of endothelial cell activation in cardiopulmonary bypass. Perfusion. 2002;17:15-21.

23. Asimakopoulos G, Taylor KM. Effects of cardiopulmonary bypass on leukocyte and endothelial adhesion molecules. Ann Thorac Surg. 1998;66:2135-44.

24. Kalawski R, Bugajski P, Smielecki J, Wysocki H, Olszewski R, More $\mathrm{R}$, et al. Soluble adhesion molecules in reperfusion during coronary bypass grafting. Eur J Cardiothorac Surg. 1999;14:290-5.

25. Morise Z, Eppihimer M, Granger DN, Anderson DC, Grisham MB. Effects of lipopolysaccharide on endothelial cell adhesion molecule expression in interleukin-10 deficient mice. Inflammation. 1999;23:99110.

26. Bach FH, Robson SC, Winkler H, Ferran C, Stuhlmeir KM, Wrighton CJ, et al. Barriers to xenotransplantation. Nat Med. 1995;1:869-73. 